\title{
Media Informasi Berupa Video Profile Bidang Pemuda Pada Dinas Pemuda, Olahraga, Kebudayaan, dan Pariwisata Kabupaten Tangerang
}

\author{
M. Puad Abdul Baqi ${ }^{1}$, Sugeng Santoso ${ }^{2}$, Muhammad Fachri Maulana ${ }^{3}$ \\ 1,2,3 Program Studi Teknik Informatika, Fakultas Sains dan Teknologi, Universitas Raharja \\ e-mail: ${ }^{* 1}$ puad@ raharja.info, ${ }^{2}$ sugeng.santoso@ raharja.info,${ }^{3}$ fachri.maulana@ raharja.info
}

\begin{abstract}
Abstrak
Pada saat ini media informasi sangat berpengaruh dalam menunjang strategi perusahaan atau instansi untuk meningkatkan daya tarik minat masyarakat khususnya memberi informasi kepada masyarakat seperti Disporabudpar bidang Pemuda yang terletak di Pusat Pemerintahan Kabupaten Tangerang, Tigaraksa, Banten. Permasalahannya adalah pihak instansi belum memiliki media penunjang informasi seperti video profil. Saat ini ada beberapa informasi yang ingin disampaikan yakni kegiatan acara dan pengetahuan tentang Disporabudpar bidang Pemuda. Penelitian ini bertujuan untuk memberikan informasi ke masyarakat yang efektif dalam menyebarkan informasi penting berupa profil pada Dinas Pemuda, Olahraga, Kebudayaan dan Pariwisata Kabupaten Tangerang khususnya di bidang pemuda. Sehingga video profile ini dirasa cukup untuk menggugah minat masyarakat, karena media informasi memudahkan pembaca dalam memahami isi pesan, dan populer di berbagai bidang. Metode yang digunakan untuk penelitian ini yakni dengan metode pengumpulan data yang terbagi menjadi observasi, wawancara, atau penelitian kepustakaan, metode analisis desain media, serta metode Konsep Produksi Media (KPM). Adapun proses perancangan penelitian ini menggunakan software Adobe After Effect dan Adobe Premiere Pro. Semoga video profil ini bermanfaat bagi Disporabudpar Kabupaten Tangerang khususnya di bidang kepemudaan, dan untuk umum khususnya kaum anak muda.
\end{abstract}

Kata kunci-Media Informasi, Video, Disporabudpar Kabupaten Tangerang

\begin{abstract}
At this time, the information media is very influential in supporting company or agency strategies to increase the attractiveness of the public's interest, especially in providing information to the public such as Disporabudpar in the Youth sector which is located in the Tangerang Regency Government Center, Tigaraksa, Banten. The problem is that the agency does not have supporting media such as video profiles. Currently there is some information to be conveyed, namely activities and knowledge about Disporabudpar in the Youth sector. When information media such as video personal data is deemed sufficient to arouse public interest, because information media makes it easier for readers to understand the contents of the message, and is popular in various fields. The method used for this research is the data collection method, namely the data collection method which is divided into observations (observations), interviews, or library research, media design analysis methods, and the Media Production Concept (MPC) method. This proves that the design of information media can continue to develop following the rapid development of technology. Disporabudpar is considered necessary to have an attractive information media, become a presentation tool, and provide information, especially for the general public. The research design process used Adobe After Effects and Adobe Premiere Pro software. Therefore, the report puts forward the topic of questions. Hopefully this profile video is useful for Disporabudpar Tangerang Regency, especially in the youth sector, and for the general public, especially young people.
\end{abstract}

Keywords - Information Media, Video, Youth, Sports, Culture, and Tourism Department

MAVIB Journal 


\section{PENDAHULUAN}

Multimedia merupakan salah satu cabang dari disiplin ilmu teknik yang menggabungkan gambar, teks, audio, dan gambar visual ke dalam suatu sistem informasi yang dapat digunakan untuk menyampaikan pesan, promosi dan informasi kepada masyarakat, informasi tersebut dapat digunakan untuk membuat gambar atau ide yang positif supaya citra pihak terkait tentang perusahaan atau organisasinya lebih luas dan aktif dikenal oleh masyarakat luas.

Disporabudpar Kabupaten Tangerang merupakan salah satu lembaga pemerintahan yang mengurus sektor pemuda, olahraga, kebudayaan dan pariwisata dalam lingkup Kabupaten Tangerang. Disporabudpar Kabupaten Tangerang berlokasi di Pusat Pemerintahan Kabupaten Tangerang Gedung Usaha-usaha Daerah Lantai 4 dengan alamat Jl. H. Somawinata No.1, Kadu Agung, Tigaraksa, Tangerang Banten.

Masalah yang terjadi saat ini adalah pihak Disporabudpar Kabupaten Tangerang belum memiliki sarana penunjang informasi seperti video profile yang memberikan informasi kepada masyarakat pada Dinas Pemuda, Olahraga, Kebudayaan dan Pariwisata Kabupaten Tangerang Bidang Pemuda. Maka dari permasalahan ini dirancang sebuah media informasi berupa video profile.

Salah satu pengaplikasian ilmu multimedia adalah membuat video profile yang bertujuan untuk menunjang informasi pada perusahaan atau instansi agar dapat menyebarluaskan berbagai informasi pada perusahaan atau instansi setempat. Informasi yang baik tentunya adalah informasi yang dapat menyajikan informasi yang akurat dan menuangkan kreativitas serta menunjukan pesan yang tepat sehingga dapat menghubungkan perusahaan atau instansi dengan masyarakat luas secara mudah yaitu salah satunya melalui video profile.

Materi video profile biasanya berisi penjelasan dan deskripsi ruang lingkup organisasi, seperti pengertian organisasi, gambaran umum, organisasi, kelebihan, dan kegiatannya, sehingga khalayak membutuhkan informasi tentang hal-hal berikut dapat menjawab. Selain itu, profile video ini merupakan solusi dari permasalahan media dan informasi promosi, dan bagian pemasaran dapat menggunakan profil video ini untuk mempromosikan kegiatannya pada acara tertentu, pameran pendidikan, dan acara lainnya. Diharapkan melalui proses pengarsipan video ini, citra Disporabudpar Kabupaten Tangerang semakin dikenal luas.

Tujuan dari perancangan video ini adalah pertama untuk memberikan kepada publik informasi yang secara efektif menyebarkan informasi penting dalam bentuk pengenalan Disporabudpar Kabupaten Tangerang (khususnya Dinas Pemuda). Kedua, untuk menarik minat masyarakat khususnya kaum muda untuk mengikuti rangkaian kegiatan. Ketiga, apa yang dibutuhkan untuk mencapai Disporabudpar Kabupaten Tangerang dalam arsip video ini diharapkan dapat memenuhi kebutuhan informasi Disporabudpar Kabupaten Tangerang khususnya di bidang kepemudaan, sekaligus meningkatkan kesan positif masyarakat. Untuk itu, rancangan video profile ini akan segera dipublikasikan melalui kanal channel YouTube dan dapat dijadikan sebagai alat presentasi bagi Disporabudpar Kabupaten Tangerang untuk menjelaskan bidang pemuda.

Informasi merupakan kumpulan fakta yang telah diolah menjadi data, sehingga dapat menjadi lebih bermanfaat dan dapat digunakan oleh siapa saja yang perlu menggunakan data tersebut sebagai pengetahuan atau dapat digunakan untuk pengambilan keputusan. ${ }^{[1]}$

Video adalah kombinasi gambar diam dan dapat dibaca sekali pada kecepatan tertentu. Gambar yang disintesis disebut bingkai, dan kecepatan pembacaan gambar disebut kecepatan bingkai, dalam satuan fps (bingkai per detik). Karena dimainkan dengan kecepatan tinggi maka akan menghasilkan ilusi gerakan yang halus.Semakin besar nilai frame rate, semakin halus pula gerakan yang ditampilkan. ${ }^{[2]}$

Dengan penelitian ini, diharapkan mampu menjawab semua persoalan yang ada pada Disporabudpar Kabupaten Tangerang. Dan penelitian ini disimpulkan dapat memberikan informasi yang jelas kepada masyarakat tentang profil Dinas Pemuda, Olahraga, Kebudayaan dan Pariwisata Kabupaten Tangerang terutama Bidang Pemuda. 


\section{METODE PENELITIAN}

Adapun metode penelitian video profile bidang pemuda meliputi: (1) Metode pengumpulan data yaitu metode pengumpulan data melalui observasi (observasi), wawancara, atau penelitian kepustakaan. (2) Analisis desain media, yaitu perangkat lunak apa pun yang digunakan untuk mengedit video. (3) Konsep produksi media (KPM). Perancangan media dokumenter telah melalui beberapa proses perancangan untuk mendapatkan pemahaman secara umum tentang proyek yang akan dihasilkan, sehingga pekerjaan pembuatan dokumenter menjadi lebih mudah. Tahapan yang dilakukan adalah pra produksi, produksi dan pasca produksi.

Beberapa penelitian yang berkaitan dengan video profile ini yaitu penelitian yang dikerjakan oleh Fadhly Abdillah, Damar Adhiguna, Agus Sevtiana (2019) "Perancangan Video Profile Sebagai Media Promosi STMIK CIC Dengan Teknik Motion Graphic Menggunakan Perangkat Lunak Komputer Graphic" Dengan Teknik Editing Menggunakan Adobe After Effect. Penelitian yang memperkenalkan apa itu STMIK CIC, kemudian di upload dalam YouTube dengan tujuan sebagai sarana publikasi kampus.

Selanjutnya, penelitian yang dilakukan Martono, dkk (2018) ${ }^{[4]}$ "Pembuatan Video Profil Sekolah Menegah Atas Negeri 7 Kota Tangerang Selatan Berbasis Audio Visual Sebagai Media Informasi dan Promosi". Tujuan penelitian ini: membantu sekolah dalam mempromosikan dan memberikan informasi tentang kondisi sekolah kepada masyarakat luas, tetapi mencapai tujuan dengan cara yang lebih kreatif dan efektif dengan biaya yang lebih rendah. Perangkat lunak yang digunakan adalah Adobe After Effects CS6.

Lalu, penelitian yang dilakukan Rifai, dkk (2018) ${ }^{[5]}$ "Pembuatan Video Company Profile Sebagai Penunjang Informasi dan Promosi Pada PT. Daiichi Elevator Indonesia". Tujuan dari penelitian ini adalah untuk memudahkan masyarakat dalam memahami segala informasi tentang perusahaan dan mempromosikan company profile-nya PT. Daiichi Elevator Indonesia. Software yang digunakan adalah Adobe Premier Pro CC 2017.

Penelitian yang dikerjakan Astriyani, dkk (2020) "Video Program Hotroom Pada Bagian Lighting Informasi Pada Metro TV". Tujuan dari penelitian ini adalah menghasilkan media pendukung informasi berupa video informasi program Hotroom Metro TV. Perangkat lunak yang digunakan dalam penelitian ini adalah Adobe Premier Pro CC 2019.

Sedangkan penelitian yang dilakukan Widada, dkk $(2020)^{[7]}$ "Video Profile Sebagai Media Promosi Pada MTs Al-Husna YPIHN Curug Kabupaten Tangerang". Tujuan dari penelitian ini adalah untuk membantu MTS Al-Husna YPIHN mengkhususkan diri pada calon mahasiswa baru. Perangkat lunak yang digunakan dalam penelitian ini adalah Adobe After Effects CS6

\section{HASIL DAN PEMBAHASAN}

\subsection{Pra-produksi}

Pra produksi merupakan langkah awal dalam proses produksi media, konsep produksi media harus direncanakan dan dipersiapkan terlebih dahulu. Ada tujuh tahapan praproduksi dalam konsep produksi media. Mulai dari ide yang akan diproduksi, kemudian dilanjutkan dengan ringkasan cerita, menulis skrip, menggambar storyboard, menulis ringkasan, mengelola staf produksi, menganalisis desain media, mengatur jadwal, dan mempersiapkan peralatan. 


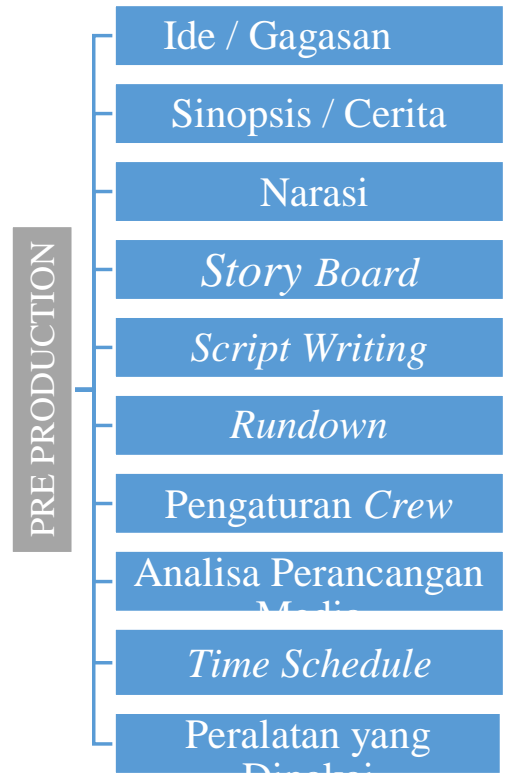

Gambar 1. Tahap Pra-produksi

1. Ide / Gagasan

Ide merupakan inspirasi yang diwujudkan dalam rencana awal proses praproduksi, yang menjadi dasar dari pekerjaan desain. Dalam penelitian ini, ide yang dibutuhkan dalam perancangan video profile bidang pemuda Disporabudpar Kabupaten Tangerang adalah menampilkan informasi dari beberapa program kerja, kegiatan, serta organisasi pada Disporabudpar Kabupaten Tangerang secara garis besar dengan visualisasi yang menarik, komunikatif dan informatif.

2. Sinopsis

Sinopsis adalah ringkasan, abstrak atau metode cerita dari sebuah video profil, dengan tetap fokus pada unsur-unsur refleksi video. Berikut adalah pendahuluannya dari Video Profile Bidang Pemuda pada Disporabudpar Kabupaten Tangerang :

"Di awal video menampilkan bumper berupa logo Kabupaten Tangerang, Footage kegiatan gladibersih kompi paskibra, dan profil Disporabudpar Kabupaten Tangerang. Selanjutnya menampilkan footage kegiatan pelantikan pengurus Forum OSIS Kabupaten Tangerang, kemudian menampilkan video kegiatan latihan outdoor paskibra. Selanjutnya menampilkan video kegiatan rapat Pembinaan Pemuda Prestasi dan menampilkan video Bkahti Pemuda Antar Provinsi sedang maju ke depan meja. Lalu menampilkan video petugas Disporabudpar Kabupaten Tangerang beserta pengurus KNPI sedang membagikan masker gratis kepada pengguna jalan raya. Kemudian menampilkan slideshow acara penyuluhan dan training anti narkoba di beberapa sekolah dan slideshow kunjungan study banding organisasi KNPI tentang UMKM ke Kota Batu, lalu menampilkan slideshow kegiatan pelatihan dan pengembangan kewirausahaan bagi pemuda Kabupaten Tangerang. Informasi didalam video profile ini melibatkan banyak pihak seperti panitia kegiatan maupun peserta kegiatan."

3. Narasi

Narasi adalah representasi dari sebuah gambaran yang berusaha menceritakan peristiwa seolah pembaca atau penonton mengalami peristiwa tersebut secara 
kronologis. Narasi tersebut juga dapat memperjelas jalan cerita dari video yang disampaikan dari awal hingga akhir. Berikut adalah uraian dalam materi video Disporabudpar Kabupaten Tangerang : Kabupaten Tangerang merupakan salah satu kabupaten yang ada di Provinsi Banten // Kota Tangerang memiliki berbagai macam kegiatan kepemudaan yang sayang untuk dilewatkan// Berbagai macam kegiatan kepemudaan telah dilaksanakan/ seperti Pasukan Paskibra yang bertugas saat Hari Kemerdekaan Republik Indonesiall Pelantikan pengurus Forum OSIS Kabupaten Tangerang // Lalu ada Pembinaan Pemuda Prestasi/ yang salah satunya adalah kesenian debus/// Ada Bhakti Pemuda Antar Provinsi/ yang siap terjun ke masyarakat// Pengurus KNPI pun ikut terjun ke jalan untuk membagikan masker.

4. Storyboard

Storyboard yaitu gambaran kasar yang berupa sketsa ditambah dengan keterangan scene baik itu dari latar tempat, angle camera, maupun kondisi saat pengambilan gambar sebelum shooting. Saat proses preproduction, rancangan storyboard ini sangat diperlukan agar hasil yang diinginkan dapat divisualisasikan dengan tepat. Dan berikut dibawah ini adalah storyboard dari Video Profile Bidang Pemuda :

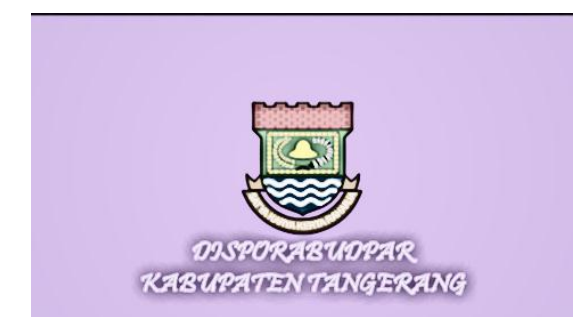

Gambar 2. Scene 1 / Lambang Kab. Tangerang

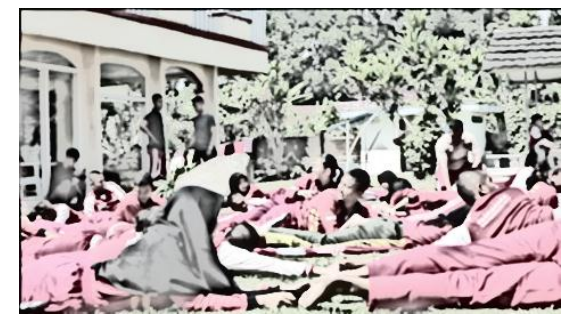

Gambar 4. EXT / Scene 3 / Eye Level View / Latihan kekompakan kompi paskibra.

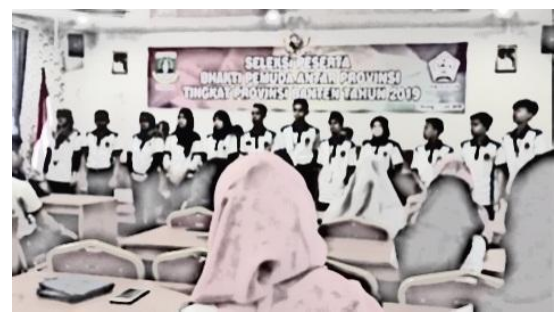

Gambar 6. EXT / Scene 5 / Eye Level View / Acara bhakti pemuda antar provinsi

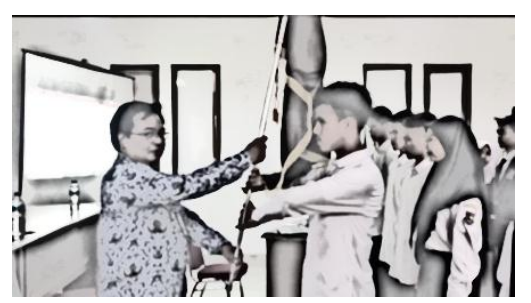

Gambar 3. INT / Scene 2 / Eye Level View / Penyerahan secara simbolis

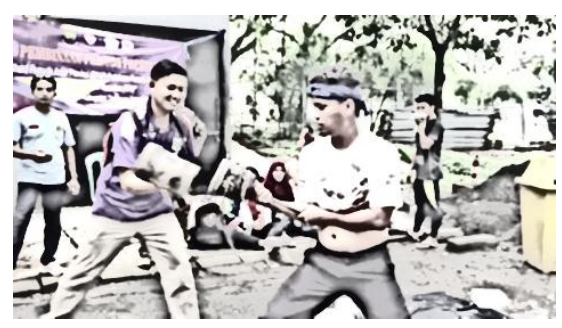

Gambar 5. EXT / Scene 4 / Eye Level View / Seseorang sedang latihan ketangkasan diri.

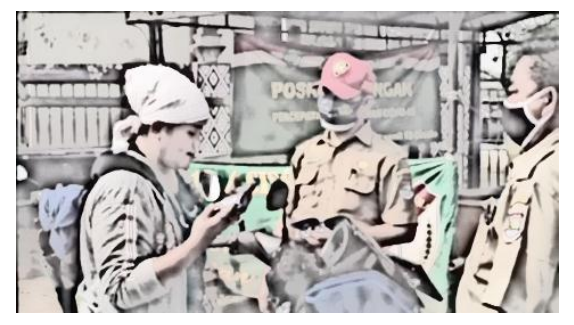

Gambar 7. EXT / Scene 6 / Eye Level View /

Seseorang sedang memakai masker 
5. Script Writing (Penulisan Naskah)

Tabel 1. Script Writing

\begin{tabular}{|c|l|c|}
\hline No & \multicolumn{1}{|c|}{ Visual } & \multicolumn{1}{c|}{ Audio } \\
\hline 1. & $\begin{array}{l}\text { Menampilkan intro bumper logo } \\
\text { Kabupaten Tangerang }\end{array}$ & Music Backsound \\
\hline 2. & $\begin{array}{l}\text { Menampilkan video penyerahan } \\
\text { simbolis bendera OSIS }\end{array}$ & Music Backsound \\
\hline 3. & $\begin{array}{l}\text { Menampilkan video latihan outbound } \\
\text { pasukan paskibra }\end{array}$ & Music Backsound \\
\hline 4. & $\begin{array}{l}\text { Menampilkan video latihan debus } \\
\text { pada kegiatan Pembinaan Pemuda } \\
\text { Prestasi }\end{array}$ & Music Backsound \\
\hline 5. & $\begin{array}{l}\text { Menampilkan video kegiatan } \\
\text { pemilihan Seleksi Peserta Bhakti }\end{array}$ & $\begin{array}{l}\text { Music Backsound } \\
\text { Pemuda Antar Provinsi Tingkat } \\
\text { Provinsi Banten }\end{array}$ \\
\hline 6. & $\begin{array}{l}\text { Menampilkan video kegiatan } \\
\text { pembagian masker untuk pengguna } \\
\text { jalan raya }\end{array}$ & Music Backsound \\
\hline
\end{tabular}

6. Rundown

Rundown merupakan susunan inti cerita dengan rancangan durasi waktu yang sesuai. Berikut Rundown dari Video Profile Bidang Pemuda :

Tabel 2. Rundown

\begin{tabular}{|c|l|c|c|l|}
\hline No. & \multicolumn{1}{|c|}{ Scene } & Duration & $\begin{array}{c}\text { INT/ } \\
\text { EXT }\end{array}$ & \multicolumn{1}{|c|}{ Description } \\
\hline 1. & Scene 2 & $00: 24-00: 35$ & INT & $\begin{array}{l}\text { Penyerahan secara } \\
\text { simbolis }\end{array}$ \\
\hline 2. & Scene 3 & $00: 40-00: 47$ & INT & $\begin{array}{l}\text { Latihan kekompakan } \\
\text { kompi paskibra }\end{array}$ \\
\hline 3. & Scene 5 & $01: 56-02: 02$ & INT & $\begin{array}{l}\text { Acara bhakti pemuda } \\
\text { antar provinsi }\end{array}$ \\
\hline 4. & Scene 4 & $00: 48-00: 53$ & EXT & $\begin{array}{l}\text { Seseorang sedang latihan } \\
\text { ketangkasan diri. }\end{array}$ \\
\hline 5. & Scene 6 & $02: 12-02: 20$ & EXT & $\begin{array}{l}\text { Seseorang sedang } \\
\text { memakai masker }\end{array}$ \\
\hline
\end{tabular}

7. Pengaturan Crew

Saat mempersiapkan staf, perlu mengatur setiap meja kerja. Proses pembuatan profil video Jobdesk meliputi sutradara, fotografer, iluminator, operator audio, penulis naskah, dan editor. Berikut komposisi staf yang terlibat dalam proses pembuatan materi video langsung untuk kaum muda :

Tabel 3. Penyusunan crew

\begin{tabular}{|l|l|l|}
\hline No & Jabatan & Nama \\
\hline 1. & Sutradara & Muhammad Fachri Maulana \\
\hline 2. & Penulis Naskah & Muhammad Fachri Maulana \\
\hline 3. & Ass. Sutradara & Tubagus Salman \\
\hline 4. & Editor & Muhammad Fachri Maulana \\
\hline 5. & Fotografer & Tubagus Salman \\
\hline
\end{tabular}


8. Analisa Perancangan Media

Dalam proses menggunakan software Adobe Premiere Pro CC dan Adobe After Effects Pro CC untuk membuat profil video ini.

9. Time Schedule (Jadwal Waktu)

Jadwal adalah alokasi waktu yang direncanakan untuk menyelesaikan seluruh proses produksi media dengan harapan dapat memenuhi jadwal yang telah ditentukan. Berikut ini adalah garis waktu dari video pengantar departemen pemuda:

Tabel 4. Susunan Acara

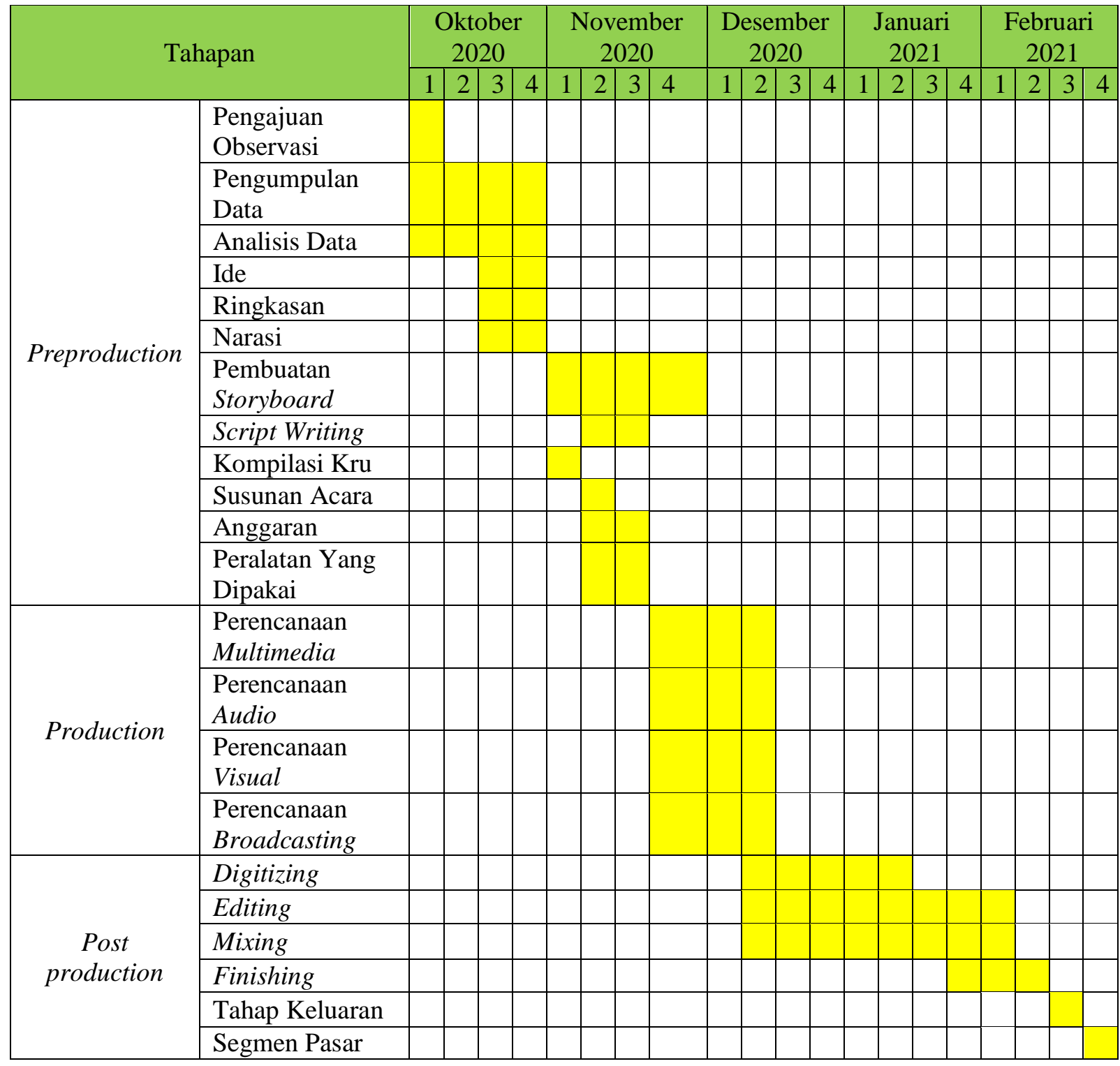

10. Peralatan yang Dipakai

Dalam proses pembuatan video profile departemen pemuda menggunakan beberapa alat seperti : Camera Canon EOS 200D, Camera Canon EOS 80D, Lensa Canon EF-M 15-45mm, Memory Card SanDisk 32GB, Tripod, Lighting, Gimbal, Laptop dan DVD RW. 


\subsection{Production}

Dalam konsep produksi media, produksi merupakan langkah selanjutnya setelah praproduksi. Dalam proses produksi, dibutuhkan kerjasama antar anggota. Padahal, tugas masing-masing anggota staf harus menjalin hubungan kerjasama yang kuat. Dalam profil video ini, perlu untuk memasukkan ide-ide yang diusulkan sebelumnya dalam proses pengambilan gambar, dan perlu untuk mempersiapkan langkah-langkah produksi dengan memperhatikan semua elemen teknis, skrip, pemain, dan fotografi yang dijalankan dan ikuti instruksi sutradara. Mengingat perlunya menyusun jalan cerita agar sesuai dengan naskah yang disiapkan pada tahap praproduksi, peran sutradara di sini sangatlah penting. Dalam tahap produksi, beberapa bagian harus disiapkan seperti tujuan media, strategi multimedia, program multimedia, audio plan, visual plan, dan broadcast plan.

Media yang dimaksudkan sebagai tujuan penelitian ini penulis informasikan kepada Departemen Pemuda dengan membuat materi video yang menarik agar masyarakat luas khususnya masyarakat di Kabupaten Tangerang mengetahui informasi tersebut. Strategi desain merupakan perumusan strategi multimedia untuk konten yang akan dirancang, disiapkan dan digunakan sebelum tahap produksi media. Program multimedia merupakan gabungan dari tiga unsur yaitu gambar / ilustrasi, teks dan audio yang dirancang untuk membuat video yang interaktif, informatif dan komunikatif.

Dalam profil video ini, rencana visual dan audio yang sesuai diperlukan untuk membuat video kaya akan konten, kreatif dan komunikatif, dan untuk mengungkapkan informasi penting yang terkandung dalam video. Audio yang digunakan dalam produksi proyek ini adalah suara alat musik dalam format mp3 dan suara latar. Suara latar yang digunakan dalam profil video berasal dari format alat musik YouTube.

Perencanaan visual merupakan proses penyusunan beberapa elemen visual yang akan menampilkan gambar, teks dan efek visual dalam video secara lengkap. Untuk memberikan kesan yang menarik kepada orang-orang, untuk meningkatkan wawasan bagi penonton, dan sebagai sarana hiburan adalah beberapa tujuan visual. Efek visual yang digunakan dalam profil video tersebut antara lain: Logo pembukaan Kabupaten Tangerang, suasana suspensi kegiatan Panitia Forum OSIS, suasana halaman, suasana kombatan yang sedang melakukan pelatihan debus, dan lain sebagainya.

Perencanaan siaran adalah tahap akhir dari proses produksi media. Dalam perencanaan penyiaran diperlukan dakwah yang memukau dan kreatif, yang tujuannya adalah untuk mencapai tujuan yang lebih luas melalui distribusi yang efektif dan efisien, sehingga dapat mewujudkan rencana penyiaran yang diharapkan.

\section{Program Visual}

Tampak pada materi video Dinas Pemuda Disporabudpar Kabupaten Tangerang ini berisi tentang logo organisasi dan beberapa contoh kegiatan yang ada. Berikut ini gambaran tampilan konten video yang dihasilkan melalui proses perancangan konsep produksi media :

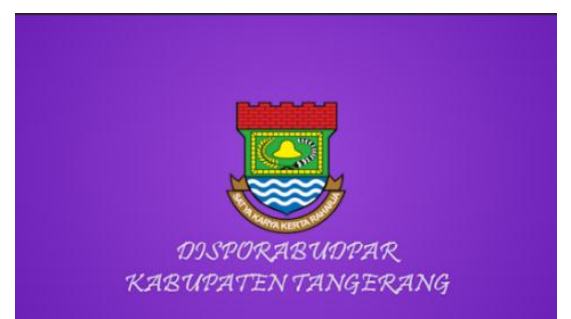

Gambar 8. Scene 1 / Logo Kabupaten Tangerang

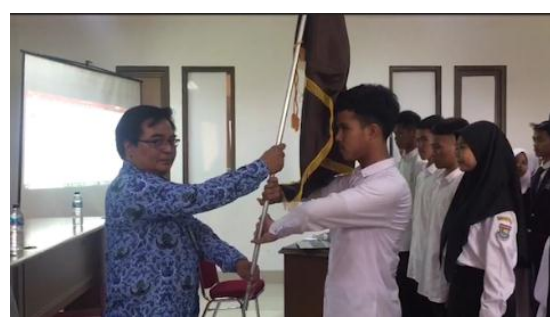

Gambar 9. INT / Scene 2 / Eye Level View / Penyerahan secara simbolis. 


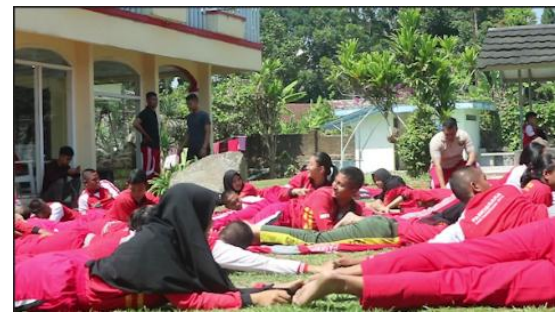

Gambar 10. EXT / Scene 3 / Eye Level View / Latihan kekompakan kompi paskibra

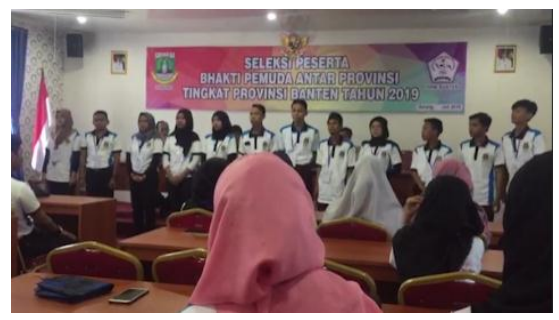

Gambar 12. EXT / Scene 5 / Eye Level View / Acara bhakti pemuda antar provinsi

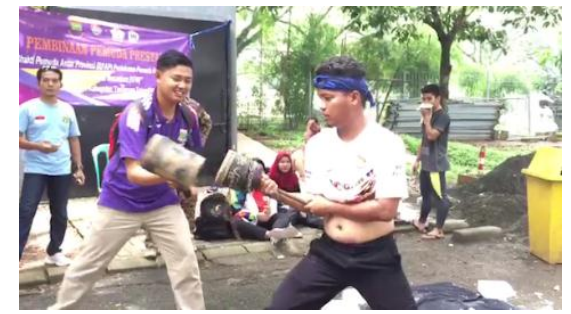

Gambar 11. EXT / Scene 4 / Eye Level View / Seseorang sedang latihan ketangkasan diri.

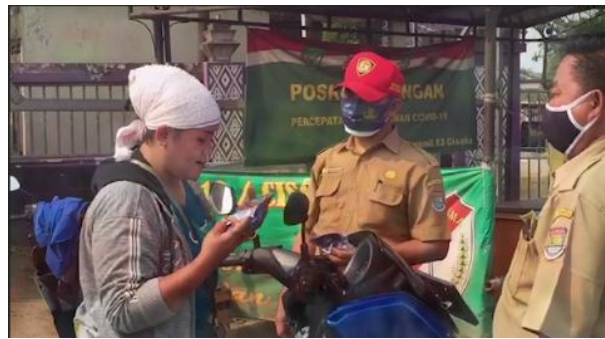

Gambar 13. EXT / Scene 6 / Eye Level View / Seseorang sedang memakai masker

\subsection{Pasca produksi}

Pasca produksi adalah proses akhir atau akhir dari tahap praproduksi dan produksi hingga video lengkap, dengan harapan dapat menyampaikan konten atau berita kepada penonton. Pada proses pasca produksi, semua gambar yang diperoleh dari proses produksi dikumpulkan dan diedit oleh editor mulai dari tahap digitalisasi hingga segmentasi pasar. Kegiatan pemutaran dan distribusi juga termasuk dalam proses pasca produksi.

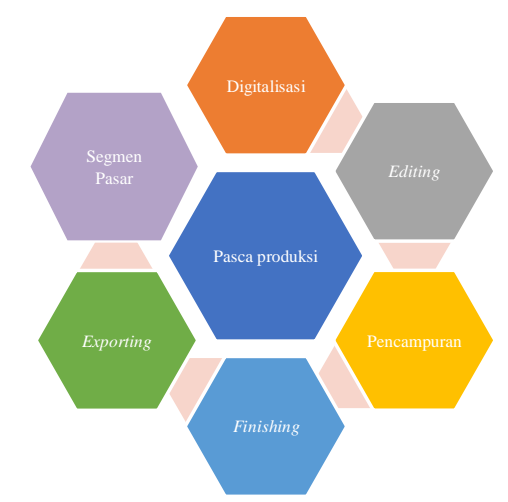

Gambar 14. Tahap Pasca produksi

1. Digitalisasi

Digitalisasi adalah proses pemindahan file gambar atau video atau data dari alat perekam (seperti kamera) ke komputer atau laptop. Proses ini harus dilakukan untuk melakukan pengeditan lebih lanjut dan mencegah kehilangan data dan kerusakan data.

\section{Editing}

Editing adalah proses mengolah data atau file dari pengambilan gambar atau pemotretan sesuai dengan desain yang telah dibuat. Mengingat banyaknya data yang akan diolah atau paling tidak data yang akan diolah, tahap editing ini harus diselesaikan setelah digitasi, dan prosesnya memakan waktu lama untuk menggabungkan file yang lengkap menjadi satu file. Pada proses ini penulis menggunakan software Adobe Premiere CC 2018 dan beberapa software lainnya untuk melakukan proses editing. 
3. Pencampuran

Pencampuran adalah proses mengumpulkan atau merangkai file yang telah diedit dan ditambah dengan teks, animasi, atau visual effect baik ingin menambahkan atau merevisi hasil editing. Dengan proses ini, maka jadilah hasil sebuah video profil yang sesuai dengan rancangan dan hasilnya dapat dilihat oleh masyarakat.

\section{Finishing}

Finishing adalah tahap pengecekan ulang oleh editor dengan tujuan untuk memastikan file yang telah diolah tidak rusak, hilang ataupun corrupt dan memastikan agar semua bagian gambar, audio maupun visual effect lainnya dapat terangkai menjadi satu sesuai dengan rancangan pada Pre Production sebelumnya.

5. Exporting

Mengekspor adalah tahap akhir dari pemrosesan gambar, video atau film. Proses ini akan mengonversi file yang diedit dari perangkat lunak Adobe Premiere Pro CC 2018 yang telah selesai. Konversikan video profil ini ke rasio 1920x1080 piksel dengan frame rate $25 \mathrm{fps}$, lalu unggah ke akun media sosial, seperti YouTube milik Disporabudpar Kabupaten Tangerang.

6. Segment Pasar

Segment Pasar adalah tahap dimana hasil rancangan video akan dipublikasikan ke masyarakat luas sesuai minat pasar yang dikemas secara menarik agar audience puas melihat hasil rancangan yang telah dibuat. Dengan video profil ini diharapkan mampu menginformasikan apa saja yang ada pada Disporabudpar Kabupaten Tangerang khususnya Bidang Pemuda.

\section{KESIMPULAN}

Menurut penelitian yang dilakukan oleh Disporabudpar Kabupaten Tangerang, yaitu dengan mengkaji materi video media informasi yang sangat membutuhkan bentuk video yaitu dengan mengajukan beberapa visual dan auditori- terkait rencana di departemen pemuda, tampilan video berubah menjadi lebih menarik dan dapat menyampaikan pesan. Agar penonton tertarik dengan profil video yang dibuat, penulis merancang konsep produksi media yang meliputi teks, gambar dan suara latar. Bertambahnya jumlah penonton merupakan salah satu harapan penulis agar masyarakat dapat memahami isi dari video yang dirancang.

\section{SARAN}

Direkomendasikan kepada Disporabudpar Kabupaten Tangerang, dan sebarkan bidang remaja lebih luas lagi dengan mengupload ke media sosial seperti YouTube, agar masyarakat luas khususnya masyarakat Kabupaten Tangerang dapat menerima informasi tersebut.

\section{DAFTAR PUSTAKA}

[1] Ramadhan, A., Ningrum, I. P., \& Yamin, M. (2016). Siaset Fakultas Teknik Universitas Halu Oleo dengan menggunakan sistem penunjang keputusan metode weighted product dan sistem informasi geografis berbasis web. SemanTIK, 2(2).

[2] Ningsih, L. N., Nugroho, R. T., \& Anjana, I. N. L. Produksi Program Musik Chamber Dalam Bentuk Video Dokumenter pada PT. Mata Air Inspirasi (SWARNA FMTV). Innovative Creative and Information Technology, 3(1), 42-57..

[3] Abdillah, F., Adhiguna, D., \& Sevtiana, A. (2017). Perancangan Video Profile Sebagai Media Promosi STMIK CIC Dengan Tehnik Motion Graphic Menggunakan Perangkat 
Lunak Komputer Graphic. Jurnal digit, 7(1).

[4] Martono, M., Triyono, T., \& Septiani, R. A. (2018). Pembuatan Video Profil Sekolah Menengah Atas Negeri 7 Kota Tangerang Selatan Berbasis Audio Visual Sebagai Media Informasi dan Promosi. Technomedia Journal, 3(1), 110-120.

[5] Rifai, D., Astriyani, E., \& Indria, U. (2018). Pembuatan Video Company Profile Sebagai Penunjang Informasi dan Promosi Pada PT. Daiichi Elevator Indonesia. Technomedia Journal, 3(1), 98-109.

[6] Astriyani, E., Fahram, M. K., \& Pebrianto, A. A. Video Program Hotroom pada Bagian Lighting Informasi pada Metro TV. Cyberpreneurship Innovative and Creative Exact and Social Science, 6(1), 33-43.

[7] Widada, S., Tama, W., Kusuma, A., \& Lestari, N. Video Profile Sebagai Media Promosi Pada Mts Al-husna Ypihn Curug Kabupaten Tangerang. Journal Cerita, 6(1), 39-51. 